patients in both groups were recorded and results were compared both within and between the groups.

Results Significant improvements were observed in both groups in morning stiffness, joint pain, Ritchie articular index, serum CRP and ESR levels compared to values before treatment, beginning from first month to sixth month $(\mathrm{p}<0.001)$. In the functional assessment; significant improvements were observed in both, determined beginning from the first month to sixth month compared to before treatment both in group receiving a night dose prednisolone and morning dose prednisolone $(\mathrm{p}<0.05)$. In comparison of morning stiffness, joint pain, Ritchie articular index and its functional assessment, and serum CRP and ESR levels in both groups, no significant difference was obtained from first month to sixth month ( $p>0.05)$.

Conclusion Low dose prednisolone therapy in treatment of RA significantly suppresses the activity of disease beginning from the first month. This condition is kept until the sixth month. However, administration of the medication either given at morning hours classically or at night according to the diurnal rhythym of disease activity doesn?t affect the results of the treatment.

\section{AB0057 POSTOPERATIVE ARTHROCENTESIS AND LAVAGE OF THE KNEE JOINT IN PATIENTS WITH RHEUMATOID ARTHRITIS AND OSTEOARTHRITIS}

AN Atanasov, PC Solakov, SI Kuzmanova, K Klinkanov, SA Andreev. Rheumatology, Medical Faculty Hospital, Plovdiv, Bulgaria

\subsection{6/annrheumdis-2001.1118}

Background The postoperative arthrocentesis (PA) and lavage (L) usually have an obligatory character after preformed arthroscopic synovectomy (AS) and debridment in RA or OA knee joints synovitis.

Objectives The aim of the study is to establish the effect of the postoperative arthrocentesis and lavage within 7 days after an arthroscopic synovectomy and debridment of the knee joint in RA and OA patients. The arthroscopic synovectomy was performed in the Clinic of Rheumatology in Plovdiv.

Methods The study includes 127 patients (73 RA and 54 OA knees). After the synovectomy a tidal lavage was done with $4 \square 5 \mathrm{~L}$ saline (Arthrotek-BiometInc. USA). During the early postoperative period within 7 days in case of a significant hydrops, tenderness and pain of the knee joint, an arthrocenteis was performed followed by an evacuation of the synovial fluid and lavage with $60 \square 100 \mathrm{~mL}$ saline.

Results Postoperative arthrocentesis and lavage was performed in all patients investigated as presented on Table 1 . In 16 patients a single arthrocentesis, in 67 patients double and in 44 patients triple arthrocenteses in the early postoperative period were needed. Improvement of the range of motion was detected in all patients but a marked improvement was establish in the single procedure patients compared to those with triple ( $\mathrm{p}<0.001)$.

Abstract AB0057 Table 1
\begin{tabular}{llllllll}
\hline 1st day & 2nd day & 3rd day & 4th day & 5th day & 6th and 7th day \\
\hline Day of PA and L & 31 & 90 & 70 & 60 & 20 & 3 \\
\hline
\end{tabular}

Conclusion In the patients who underwent an arthroscopic synovectomy of the knee joint was necessary to be performed most frequently two or three times postoperative arthrocenteses and lavage. An early improvement of the range of motion, as well as a postoperative recovery are achieved, especially in the single procedure RA and OA patients.

\section{REFERENCES}

1 Ayral X, Dougados M. Joint lavage. Rev Rhumatisme (Engl. Ed.). 1995;62:281-7

2 Ike R, Arnold WJ, Rotschild EW, et al. Tiadl irrigation versus conservating medical menagement in patients with osteoarthritis of the knee. J Rheumatol. $1992 ; 19: 772-9$

\section{AB0058 CYTOPENIA ASSOCIATED WITH LOW DOSE PULSE METHOTREXATE IN THE TREATMENT OF RHEUMATOID ARTHRITIS}

S Nakazaki, T Murayama, S Katoh. Rheumatology and Collagen Disease, Kanazawa Rehabilitation Hospital, Kanazawa, Japan

10.1136/annrheumdis-2001.1119

Background MTX has gained wide acceptance of the most useful disease-modifying anti-rheumatic drugs. But, MTX cause serious toxicities including hepatic abnormalities, pneumonitis, and myelosuppression.

Objectives To assess the associated risk factors of methotrexate (MTX)-induced cytopenia in rheumatoid arthritis (RA).

Methods We followed 420 patients started on MTX for RA. We evaluated the frequency and clinical significance of patients with cytopenia related to MTX therapy.

Results The prevalence of patients remaining in the follow-up in the MTX treatment was $21 \%$ at 60 months. A total of 10 patients with cytopenia related to MTX therapy were identified among them. The prevalence of cytopenia, including leukopenia $(\mathrm{n}=6)$, thrombocytopenia $(\mathrm{n}=3)$ and pancytopenia $(\mathrm{n}=1)$, estimated to be $2.4 \%$ in MTX treated RA patients.

Patients with cytopenia received $2.5 \square 8 \mathrm{mg} / \mathrm{w}$ over a mean duration of 60.0 months (10 $\square 119$ months). Nine of 10 patients received NSAIDs with MTX therapy. The presence of renal abnormality $(\mathrm{Cr}>1.2 \mathrm{mg} / \mathrm{d}$ ) was in 3 cases, age over 70 years old in 4 patients, body weight under $50 \mathrm{~kg}$ in 8 patients, mean corpuscular volume (MCV) over $100 \mathrm{fl}$ in 2 patients. High MCV value (over $94 \mathrm{fl}$ ) was in 7 patients, 6 of whom had some symptoms including fever $(\mathrm{n}=3)$ and oral mucosa/lip abnormalities $(\mathrm{n}=3$ ). Low MCV value (under $84 \mathrm{fl}$ ) was in 3 patients, who had no symptoms but arthralgia and no renal abnormality. And they were younger and received MTX in shorter period than high MCV group.

Conclusion In patients with high MCV (over $94 \mathrm{fl}$ ), most haematological toxicities seen during the course of MTX therapy can be predictable. But, some patients may develop unpredictable haematological reaction.

\section{REFERENCES}

1 American College of Rheumatology ad hoc Committee on Clinical Guidelines. Guidelines for monitoring drug therapy in rheumatoid arthritis. Arthritis Rheum 1996;39:723-31

2 Gutierrez-Urena S, Molina Cesar JF, Garcia O. Pancytopenia secondary to methotrexate therapy in rheumatoid arthritis. Arthritis Rheum. 1996;39:272-6 


\section{AB0059 COMBINATION OF PLASMAPHERESIS AND INTRAVENOUS BOLUS ADMINISTRATION OF METHOTREXATE AND METHYLPREDNISOLONE IN REFRACTORY RHEUMATOID ARTHRITIS}

HA Asseeva, SK Soloviev, AS Chiklikchy. Of the Intensive Therapy, Institute of Rheumatology, Moscow, Russia

10.1136/annrheumdis-2001.1120

\section{Background}

Objectives To evaluate the effect of synchronic program of intensive therapy (SPIT) on patients with refractory RA.

Methods 20 RA patients with systemic manifestations: rheumatoid nodules (65\%), lymphadenopathia (45\%), fever (35\%), livedo vasculitis (10\%). 19 patients (95\%) demonstrated intorelability of inefficacy of previous basic therapy, 6 (30\%) had a corticosteroid dependency. Before the treatment Wilke?s Index activity was 7,06 , Index severity was $11,38.6$ courses of plasmapheresis synchronised with pulse-therapy of Methylprednisolone $(1500 \mathrm{mg})$ and Methotrexat $(240 \mathrm{mg})$ during 1 month, after that all patients were prescribed Methotrexat in dosage of 20 mg i.m. for 11 months.

Results 4 patients (20\%) had a clinico-laboratory remission in a year after beginning of treatment (Wilke,1993). In all group clinico-laboratory improvement was observed in a month and prolonged during the year. In all causes were no systemic manifestations in a month of the treatment. All 20 patients demonstrated the significant decrease of arthralgies, morning stiffness, number of inflamed joints, growth of indices of functional activity. Prednisolone was abolished in 2 patients and daily dosage was decreased in 4 patients/In a 6 months 16 patients $(80 \%)$ had a low clinico- laboratory activity. Side effects were minimal and were arrested without additional treatment.

Conclusion Synchronic program of intensive therapy can be considered the effective method of RA therapy enabling to achieve speedy clinical improvement, espessially during severe variants of the disease progressing with systemic manifestations, resistance to basic medication, corticosteroid dependency.

\section{AB0060 INTRAVENOUS PULSE OF METHOTREXATE AND METHYLPREDNISOLONE/DEXAMETHASONE IN THE TREATMENT OF SEVERE RHEUMATOID ARTHRITIS}

SK Soloviev, NY Nykishina, EA Asseeva. Of the Intensive Therapy, Institute of Rheumatology, Moscow, Russia

\subsection{6/annrheumdis-2001.1121}

\section{Background}

Objectives To assess the effect of combination of high doses of Methotrexate and Pulse-therapy of corticosteroids in 12 months $\phi$ trial.

Methods Thirty one patients with systemic rheumatoid arthritis, resistance to basic medication, corticosteroid dependency were included into the study. Intravenous (i.v) pulse-therapy was provided for 3 days by methylprednisolone of $15 / \mathrm{mg} / \mathrm{kg} / \mathrm{d}$ or dexamethasone of $2 / \mathrm{mg} / \mathrm{kg} / \mathrm{d}$. Methotrexate of $100 \mathrm{mg}$ i.v. was administrated on 7 and 30 days of the treatment, after that all patients were prescribed Methotrexat in dosage of $20 \mathrm{mg}$ i.m. for 11 months.

Results Clinical effects of treatment and the regression of inflammatory activity were rapid and excellent in 1 month and prolonged during $6 \square 12$ months. There was $20 \%$ improvement in the joint pain index and joint swelling index in $>95 \%, 45 \%$,
$65 \%$ of the patients in a $1,6,12$ months therapy respectively. In a year was observed the significant decrease of Wilke?s Index activity and Index severity. There were a marked fall in ESR, CRP and TNF. 12 pts had no radiographic progression in one year therapy. Side effects were minimal, In $43 \%$ causes were observed dyspepsia.

Conclusion Intravenous pulse of methotrexate and methylprednisolone/dexamethasone in the treatment of severe rheumatoid arthritis appeared to be useful regimen in the treatment of rheumatoid arthritis with systemic manifestations, resistance to basic medication, corticosteroid dependency.

\section{AB0061 CIRCULATING ADENOSINE LEVELS AFTER INITIATION OF METHOTREXATE AND ANTI-TNF THERAPY IN RA}

P Barrera, AE Van Ede, M Creemers, RF Laan, RA De Abreu, LB Van de Putte. Rheumatology, University Medical Center Nijmegen, Nijmegen, The Netherlands

\subsection{6/annrheumdis-2001.1122}

Background Adenosine exerts strong anti-inflammatory effects.

In vitro and animal studies suggest that adenosine release is implicated in the mechanism of action of methotrexate (MTX) and sulfasalazine. Whether blocking TNF has any effect on this pathway has not been investigated yet.

Objectives To assess the short anf mid-term effect of MTX and anti-TNF therapy on the circulating levels of adenosine and aminoimidazolcarboximide ribotide (AICAR) in rheumatoid arthritis (RA).

Methods Patients starting therapy with MTX ( $\mathrm{n}=10$; dose 15 $\mathrm{mg} / \mathrm{kg} \mathrm{im}$ ) or infliximab ( $\mathrm{n}=10$, dose $3 \mathrm{mg} / \mathrm{kg}$ ) were enrolled in the study. Blood samples were drawn immediately before and 2, 6, 24 and $48 \mathrm{~h}$ and 4 weeks after the first administration of MTX or anti-TNF. Measurements before and 2 and $6 \mathrm{~h}$ after administration were also performed on week 12 . To avoid adenosine degradation, blood was directly mixed with a solution containing EHNA $10 \mu \mathrm{M}$, dipyridamole $20 \mu \mathrm{M}$ and indomethacin $2 \mathrm{mg} / \mathrm{L}$. Adenosine and AICAR were measured using sensitive HPLC methods. Response to therapy was assessed at week 4 and 12 using the EULAR criteria.

Results Baseline adenosine levels were similar in both patient groups (median, [p25 - p75] 213 [146 - 302] and 230 [71 291] $\mathrm{nmol} / \mathrm{L}$ for MTX and anti-TNF respectively). Adenosine levels showed marked inter- and intra-individual variability $(75 \%$ and $49 \%$ respectively). In 3 patients, adenosine concentrations raised markedly $2 \mathrm{~h}$ after the first MTX dose. Nevertheless, no consistent changes were observed in the whole MTX group or after anti-TNF administration.

Within the study period, $55 \%$ and $64 \%$ of the patients receiving MTX and anti-TNF showed clinical response. The latter was also not reflected in the levels of adenosine. AICAR could not be detected in any of the samples.

Conclusion In patients with RA, neither MTX therapy nor its effectivity are mirrored by consistent changes in circulating adenosine levels. The same holds true for anti-TNF treatment. This does not exclude the possibility of a modulation of adenosine release at the target organ. 